\title{
Malignant Pericarditis
}

National Cancer Institute

\section{Source}

National Cancer Institute. Malignant Pericarditis. NCI Thesaurus. Code C7753.

Pericarditis caused by the infiltration of the pericardium by a malignant neoplasm. The diagnosis is based on the cytological examination of pericardial fluid or the histologic examination of pericardial tissue. 